\title{
A Sheep Model for the Osseointegration of PEO-treated Gamma Titanium Aluminide
}

\author{
Paola A. Richiez-Nieves, Irimar Torres-Zapata, Abner A. Rodríguez, Héctor R. Pérez, Zilma J. \\ Poueymirou, Nanette Diffoot-Carlo and Paul A. Sundaram
}

\section{ABSTRACT}

A sheep model was used to study the osseointegration of gamma titanium aluminide ( $\gamma$ TiAl) screws subjected to plasma electrolytic oxidation (PEO). The degree of osseointegration was determined by measuring the maximum torque for screw removal from bone after 3 and 6 months of implant placement in sheep for PEO-treated $\gamma$ TiAl, untreated $\gamma$ TiAl, and untreated Ti6Al4V cortical screws. The amount of bone growth and mineralization were qualitatively observed by von Kossa staining of the bone tissue in the region surrounding the implants. Inductive Coupled Plasma-Optical Emission Spectroscopy (ICP-OES) was carried out to determine trace amounts of metallic elements in blood serum samples obtained from the animals. Generally $\mathrm{Al}, \mathrm{Cr}$ and $\mathrm{V}$ were present in blood serum in comparable quantities in the control and implanted animals, while neither Ti nor $\mathrm{Nb}$ was detected. Results from histological analysis and SEM images indicated that de novo bone growth occurred to a greater extent for the PEO treated $\gamma$ TiAl screws. Furthermore, the torque for screw removal from bone was significantly higher $(p<0.05)$ for the PEO-treated $\gamma$ TiAl implants. Taken together, the data supports that the PEO surface treatment enhanced osseointegration to a considerable degree indicating the potential for favorably utilizing PEO-treated $\gamma$ TiAl for dental and orthopedic implant applications.

Keywords: Gamma titanium aluminide, Osseointegration, Plasma Electrolytic Oxidation, Sheep model
Published Online: June 8, 2020

ISSN: $2684-4443$

DOI $: 10.24018 /$ ejdent.2020.1.3.8

\section{P. A. Richiez-Nieves}

UPR-Medical Sciences Campus, PR USA.

(e-mail: paola.richiez@upr.edu)

I. Torres-Zapata

UPR-Mayaguez, PR USA.

(e-mail: irimar.torrres@upr.edu)

A. A. Rodriguez

UPR-Mayaguez, PR USA.

(e-mail: abner.rodriguez3 @upr.edu)

H. R. Pérez

Santa Lucia Veterinary Services, PR USA.

(e-mail: hector.perez.svsl@gmail.com)

Z.J. Poueymirou

UPR-Mayaguez, PR USA.

(e-mail: zilma.poueymirou@upr.edu)

N. Diffoot-Carlo

UPR-Mayaguez, PR USA.

(e-mail: nanette.diffoot@upr.edu)

P.A. Sundaram*

UPR-Mayaguez, PR USA.

(e-mail: paul.sundaram@upr.edu)

*Corresponding Author

\section{INTRODUCTION}

The popularity of titanium alloys for dental and orthopedic implant applications has been opaqued by biocompatibility issues [1-3]. When considering such implants in the long term, corrosion and wear either individually or in combination have been the bane of these alloys which has cast serious doubts on performance in the long run [4,5]. The accumulation of corrosion/wear debris in peri-implant tissue has resulted in the manifestation of systemic effects [6,7]. Furthermore, inflammation accompanied by cytotoxicity in tissues surrounding the implants has been reported to lead to implant loosening, which normally requires compulsory revision surgery which is painful and expensive [3]. Barrier coatings have been recommended as a remedy to overcome the problem of corrosion/wear [8,9] but such surface techniques have ultimately resulted in poor adherence of the coating and heterogeneity in properties as a result of manufacturing techniques $[10,11]$. One exception appears to be plasma electrolytic oxidation (PEO) which has shown promise by significantly improving corrosion and wear resistance of these titanium alloys [10-12]. Of course, the ceramic oxide formed as an end result of the PEO process not only serves as a barrier coating to the aggressive solutions in the human body environment but the incorporation of calcium and phosphorus appear to increase biocompatibility especially in implants focused toward hard tissues. The purpose of this research is to study the potential for osseointegration of a new vanadium-free titanium alloy called gamma titanium aluminide ( $\gamma \mathrm{TiAl}$ ) whose osteoconductivity is further enhanced with the PEO treatment via calcium and phosphorus deposition expected to induce bone formation on the implant surface while providing protection from corrosive agents within the human body. PEO treated $\gamma$ TiAl and untreated screws made from $\gamma$ TiAl and Ti6Al4V were implanted in the sheep model to test and compare the degree of osseointegration with the objective of exploring the potential of PEO treated gamma titanium aluminide ( $\gamma \mathrm{TiAl})$ 
for dental and orthopedic implant applications.

\section{MethodS AND MATERIALS}

\section{A. Implant design and surface treatment}

The implant screw with a length of $14 \mathrm{~mm}$, a diameter of 3.5 $\mathrm{mm}$ and a core of $2.5 \mathrm{~mm}$ was designed based on an earlier report [13]. The screws were machined from as-received bars of Ti6Al4V and $\gamma \mathrm{TiAl}$ of approximately $25 \mathrm{~mm}$ diameter using EDM. Figure 1a is a CAD-based drawing of the implant screw. These are standard implant crews and are not self-tapping. The screw heads were slightly different for each alloy in order to distinguish them during implant retrieval. The PEO surface treatment was applied to six (6) $\gamma \mathrm{TiAl}$ screws using a customized set-up. SBF electrolytic solution was placed in a modified glass beaker and the screws to be treated were attached one at a time to the positive end of the power supply (Hoeffer PS-300B, Cambridge, MA) and dipped into the solution. The negative end was placed in contact with the solution at least $25 \mathrm{~mm}$ from the screw. After initial experimentation, an applied current of $270 \mathrm{~mA}$ and a treatment time of 120 seconds were selected to generate a continuous oxide coating on the screw surface.

\section{B. Animal Model}

Three adult cross-bred sheep were used for the animal model. Their average age was 2-3 years and their average weight was $40 \mathrm{~kg}$. The Ti-alloy based screws were placed in two of the three sheep, while the third was used as control primarily for serum analysis. All animal experiments were conducted according to IACUC approved protocol at the University of Puerto Rico at Mayaguez (No. 20140123A). A pelvic model was used to test the implants. The screws were placed in the right iliac wing of the os coxae of each sheep. As part of the pre-surgical protocol, all screws were washed with ethanol, placed in aluminum foil, identified and sterilized in preparation for implantation. The sheep were isolated two days prior to and in preparation for surgery. Food was withheld for 24 hours and water for 8-12 hours before anesthetic induction. A physical examination was performed and blood samples were collected for analysis.

The animals were sedated with Xylazine (0.1-0.22 mg/kg IV) which provides analgesia, sedation and recumbence. After recumbency was achieved propofol (4-6 mg/ $\mathrm{kg} \mathrm{IV}$ ) was administered at $25 \%$ of the calculated dose every 30 seconds until the desired effect of light anesthesia was achieved. When animal showed light anesthesia, isoflurane was used in conjunction with propofol. While initial anesthetic induction was achieved with propofol, anesthesia was continued with isoflurane using a mask. The induction rate was initiated at $5 \%$ isoflurane and later reduced to $2 \%$ for maintenance during the surgical procedure. A standard rebreathing system was used with a soda lime container and a $3 \mathrm{~L}$ rebreathing bag. Atropine $(0.15-0.3 \mathrm{mg} / \mathrm{kg} \mathrm{IM})$ and lidocaine $(2 \mathrm{mg} / \mathrm{kg})$ were used locally on the area where the surgical incision was made. Flunixin Meglumine (1.1 $\mathrm{mg} / \mathrm{kg} \mathrm{IM})$ was also given as analgesic.

\section{Surgery}

The sheep was placed on lateral left recumbence and the neck was elevated using a towel to allow drainage of saliva and ruminal content in order to diminish the possibility of respiratory problems from aspiration. A rectal thermometer and pulse oximeter were used to observe $\mathrm{SpO}_{2}$ which was kept at above $90 \%$ with a respiratory rate of approximately 40 breaths per minute. An Animal Health Technician (AHT) monitored the supply of anesthetic during surgery. Anesthetic depth of the animal was verified by one or more of the following: palpebral reflex (present under light anesthesia), central positioning of eyes with dilated pupils (indicative of deep anesthesia), passive regurgitation of ruminal contents seen by continuous flow of fluid in mouth (indicative of deep anesthesia), observation of spontaneous movements, chewing motions and active regurgitation which are signs of light anesthesia.

After shaving (circumferentially from dorsal midline to the distal portion of the femur and approximately $10 \mathrm{~cm}$ cranial of the iliac crest and $2-3 \mathrm{~cm}$ caudal to the greater trochanter), cleaning, scrubbing and preparing the surgical site, the sheep was submitted to surgery. A straight skin incision of approximately $20 \mathrm{~cm}$ was made over the area of the gluteal muscles. The subcutaneous tissue and fascia were separated in the line of the skin incision using Metzenbaum scissors. The tensor fasciae latae muscle and the middle gluteal muscle were separated cranially and superficial gluteal muscle caudally. With blunt dissection the medial and deep gluteal muscles were separated and elevated from the lateral surface of the ilium without cutting the muscles to allow exposure of the surface of the bone. Hohmann retractors were used to hold the muscles in place to maintain exposure of the ilium surface into which the titanium screws were implanted. A total of nine surgical screws were placed in random order, three (3) each of Ti6Al4V, three (3) each of $\gamma \mathrm{TiAl}$ with PEO treatment and three (3) each of $\gamma$ TiAl without PEO treatment. (a)

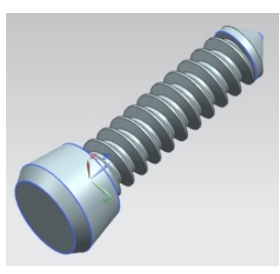

(b)

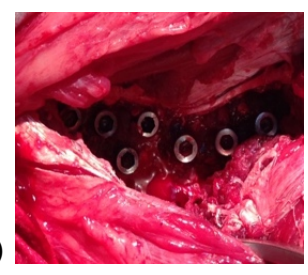

(c)
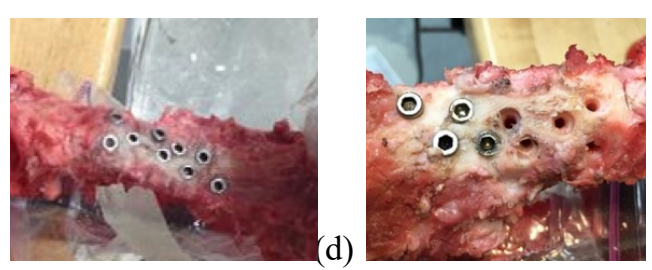

Figure 1. (a) CAD-based drawing of the implant screw, (b) Screw implanted in random order in the ilium of the sheep, (c) Implants after extraction from pelvic region and removal of appositional bone growth, and

(d) Region of implantation after removal of some implant screws.

An orthopedic drill bit of appropriate size (diameter $=2.5$ $\mathrm{mm}$ ) was used to make the holes on the surface of the ilium. The drill bit was attached to a Jacobs pin chuck that was also attached to a Makita ${ }^{\circledR}$ orthopedic drill. A soft tissue protector sleeve was used to help prevent catching and tearing soft tissue and muscles while drilling the holes in the bone. After each hole was made, a surgical screw implant was placed using the appropriate hex screwdriver by hand to avoid excessive torque and damage to the screws. After placing all 
the implants, the area was examined, pressure was placed with sterile gauze to stop excessive bleeding and muscles were released to allow coverage of exposed bone. Figure $1 \mathrm{~b}$ shows the placement of screws in the ilium of the sheep. The incisions were closed in layers: tensor fasciae, subcutaneous tissue and skin. The suture used was Vicryl (size 0) with a simple interrupted suture pattern for internal layers and an interlocking ford pattern to close the skin layer.

\section{Animal Recovery}

The animal was repositioned in sternal recumbency to allow ruminal gas to escape. It was then placed in a warm environment with blankets or external heating sources as needed. The post-operative analgesia was provided by Flunixin Meglumine (1.1 mg/kg IV) every 12 hours. The post-operative antibiotics and medications used were the following: Florfenicol (20 mg/ $\mathrm{kg}$ IM) for 3 consecutive days, Dexamethasone ( $2 \mathrm{mg} / \mathrm{ml})(20-30 \mathrm{mg}$ IM) every 24 hours for 2-3 days. The sheep was kept under observation for 24 hours after surgery. Feed and water were offered after the animal fully recovered from anesthesia.

The three sheep ( 2 with implants and 1 control) were kept in individual stalls after recovery. Tropical grass hay was offered ad libitum. The animals were supplemented with 250 $\mathrm{g}$ /day of commercial concentrate and a mineral block. Vitamin A, D and E were injected intramuscularly every 21 days. Anthelmintic was injected every 21 days when necessary based on coloration of ocular mucosa according to FAMACHA method. Water was always available. The sheep were evaluated frequently for discomfort and pain by a licensed veterinarian. Urine and blood samples were collected biweekly until time of sacrifice. The first sheep was sacrificed after 3 months and the second after 6 months. Once a sheep was sacrificed, the pelvic bone was harvested and prepared for screw removal. Both hard and soft tissue which had covered the implant screws were scraped off with a metal brush. Figure $1 \mathrm{c}$ indicates the presence of the implants after this process.

\section{E. Torque removal test}

The first part in the determination of the biocompatibility of each type of screw was the measurement of the removal torque. A Omega HHTQ35 torque meter was placed on the screw and rotated counter-clockwise while the bone was held on either side by a press. The removal torque was the highest torque that the digital meter marked while removing each screw. These values were recorded. Figure $1 \mathrm{~d}$ is an image of the implant region after some of the screws were removed during the torque test.

\section{F. Histology}

The bone was sectioned around implant holes into $18 \times 18$ x $5 \mathrm{~mm}$ cubes with a $546 \mathrm{Rip} /$ Crosscut blade mounted on a DREMEL 8100. Once cut, each bone cube was placed in 10 $\%$ formalin neutral buffer and transported to the histology laboratory. It was then transferred to the decalcifying solution (Cal-Ex II) and left for 4-7 days depending on bone thickness. The bone was later washed with running distilled water and placed in formalin solution. The samples were placed in the Autotecnicom ${ }^{\circledR}$ tissue processor for 24 hours followed by paraffin inclusion. The bone was cut into $4 \mu \mathrm{m}$ sections perpendicular to screw axis and stained with a commercial NovaUltra von Kossa staining kit. A black/gray coloring corresponds to bone mineral formation, whereas nuclei stain red and the cytoplasm stains pink in histology images with von Kossa staining.

\section{G. Blood serum analysis}

Blood samples were collected from the jugular vein using a 20-gauge needle with a Vacutainer ${ }^{\mathrm{TM}}$ tube without anticoagulant additive and placed in ice. The samples were taken to the laboratory for centrifugation to obtain blood serum for chemical analysis. To convert the serum samples into solutions for elemental analysis, microwave acid digestion method was employed using concentrated $\mathrm{HNO}_{3}$ and concentrated $\mathrm{H}_{2} \mathrm{O}_{2}$ [14-17]. A MARS Xpress Technology Inside Microwave System was used to perform the extraction employing the EPA 3051 method. To perform the extraction $0.5 \mathrm{~mL}$ ovine blood aliquots were mixed with $2.0 \mathrm{~mL}$ of $65 \%$ $\mathrm{v} / \mathrm{v} \mathrm{HNO}_{3}$ plus $1.0 \mathrm{~mL}$ of $30 \% \mathrm{v} / \mathrm{v} \mathrm{H}_{2} \mathrm{O}_{2}$ in a polypropylene extraction vessel. The mineralization was completed according to the following program: control temperature of $100{ }^{\circ} \mathrm{C}$, a ramp time of $5.5 \mathrm{~min}$ to reach $160 \mathrm{~W}$ and 9.5 minutes in hold. After completing the digestion, the vessels were cooled, and the contents were filtered using $2.5 \mu \mathrm{m}$ filter paper (Whatman \#42) and transferred to calibrated centrifuge tubes and diluted to $10 \mathrm{~mL}$ with deionized water. The samples were stored in the refrigerator at $4^{\circ} \mathrm{C}$ until ICP-OES analysis, to observe the concentration of $\mathrm{Ti}, \mathrm{Al}, \mathrm{V}, \mathrm{Cr}$ and $\mathrm{Nb}$ in the serum. This was repeated for all samples. Once filtered, the element concentration in each was measured with a PerkinElmer Optima 7300 DV ICP-OES. Calibration curves were generated from the preparation of five multi-elemental standard solutions at concentrations of $0.10,0.30,0.50,0.75$ and $1.00 \mathrm{ppm}$ of Ti, $\mathrm{V}$ and $\mathrm{Nb}$ as well as $0.20,0.60,1.00,1.50$ and $2.00 \mathrm{ppm}$ of $\mathrm{Al}$ and $\mathrm{Cr}$. These were prepared by diluting a certified standard solution (Sigma Aldrich, US) of each element to be analyzed and deionized water and dissolvent. In the study, analytical lines of the greatest intensity of emission were used to obtain a directly proportional relation between analyte concentration and instrument response. The concentrations were documented and analyzed to determine if amounts were normal and within acceptable limits.

\section{RESUltS AND DisCUSSION}

Osseointegration is the gold standard in the use of implants in both dental and orthopedic applications. An enhanced degree of osseointegration of an implant can be achieved if a strong chemical bonding is possible between the bone tissue and the implant surface. Over the last decade, sheep have been used to study implants in bone because of similarity in body weight and bone length to humans [18], although bone density in sheep is reported to be higher [19]. For titanium screws, a delay in loading soon after implantation is recommended to produce a desirable, intimate contact between the tissue and the implant [20]. Based on Bränemark's principles, a two-stage implantation procedure is recommended for an initial unloaded implant followed by loading in the second stage for enhanced osseointegration [20]. Although there is no general agreement on the duration of the no-load stage, obviating this step and immediately loading the implant results in the formation of a fibrous tissue between the implant and the bone which is known to be detrimental to osseointegration [21]. In the present study, the sheep were allowed to move about in their individual enclosures one day after surgery. After the sheep were 
sacrificed, the pelvic bone was extracted and torque removal tests were conducted on the implanted screws, some of which were examined under an SEM after extraction. Scanning electron microscopy of the extracted titanium screws after the 3-month implantation period (see Figure 2) did not reveal the formation of a fibrous tissue at the implant interface both for the untreated and PEO-treated cases as suggested [21]. In fact, Figure 2a and Figure 2b show evidence of small amounts of bone residue attached to the surface of the implants screws after removal for both untreated Ti6Al4V and $\gamma \mathrm{TiAl}$ titanium alloys indicating a small degree of osseointegration. However, in the case of the PEO-treated $\gamma \mathrm{TiAl}$, there appears to be intimate contact between the bone tissue and the screw surface $[22,23]$ evidenced by fracture occurring in the bone tissue near the implant surface. If the bone was not strongly bonded to the implant surface, fracture would have occurred at the implant surface during the torque removal test. In this case it is clear from the SEM images in Figure $2 c$ that the fracture occurred in the region of the bone and this tissue appears to be trabecular in nature. It must be emphasized that once the animals were sacrificed and the ilia with the implants were retrieved, appositional bone growth occurred and the screw heads were completely covered with bone indicating that there are no biocompatibility issues with any of the implant materials. Before torque removal tests, the muscle tissue covering the implants were removed and the appositional bone was scraped off with a metal wire brush to reveal the heads of the implant screws. The torque removal data for the three types of screws is given in Table 1.

The torque measurements for screw removal of both Ti6Al4V and $\gamma$ TiAl without treatment is similar for both implantation periods ( 3 and 6 months). It must be noted that these maximum torque values are much higher than those reported in literature for various metallic implants for a 2month implantation period [13]. Another study for pull-out values indicate that a 1-month implantation period is not sufficient for osseointegration in sheep [19]. The higher maximum torque values in the present study appear to indicate that there is probably formation of a larger amount of trabecular bone in the peri-implant region during the threemonth implantation period in the case of untreated screws used in this study. However, this may not be necessarily congruent with a greater degree of osseointegration of the untreated titanium implants. The resistance to the applied torque for screw removal may merely be a consequence of the frictional interaction between the implant surface and the de novo bone tissue being generated and not necessarily due to osseointegration of the implant. A two-factor ANOVA was performed with the maximum torque values for screw removal in this study for the sheep model as given in Table 1. Results indicate that there is a greater variance in maximum torque due to the type of treatment $(p=0.008)$ compared to that resulting from the period of implantation $(p=0.08)$. Increase in implant duration from 3 months to 6 months does not necessarily improve osseointegration significantly $(\mathrm{p}=0.08)$. In contrast, the maximum torque value is definitely greater for PEO-treated $\gamma \mathrm{TiAl}$ compared to the untreated screws $(\mathrm{p}=0.008)$ implying enhanced bonding at the PEOtreated implant interface as observed in Figure 2c. Preferential fracture occurring in bone (possibly trabecular) as opposed to the bone-implant interface during testing is clear evidence that the PEO treatment is effective in enhancing osseointegration of the $\gamma \mathrm{TiAl}$ screw unlike the other two cases.

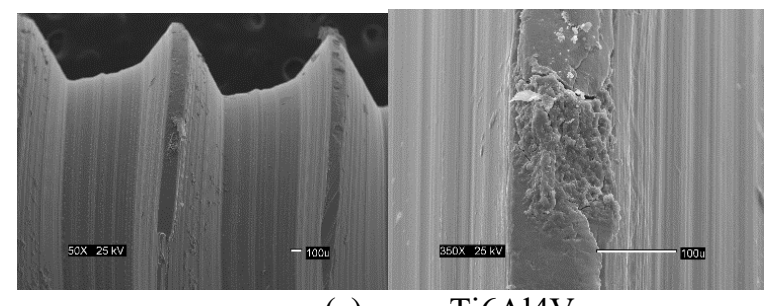

(a)

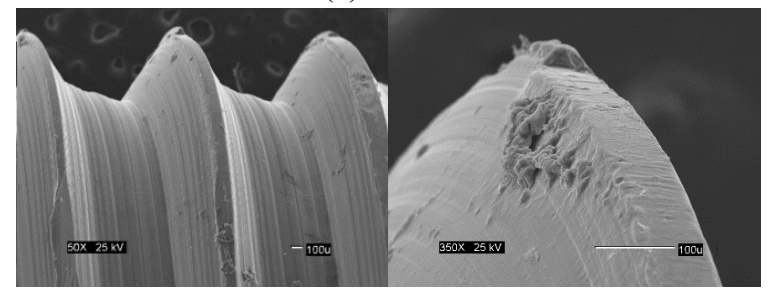

(b)

Gamma TiAl

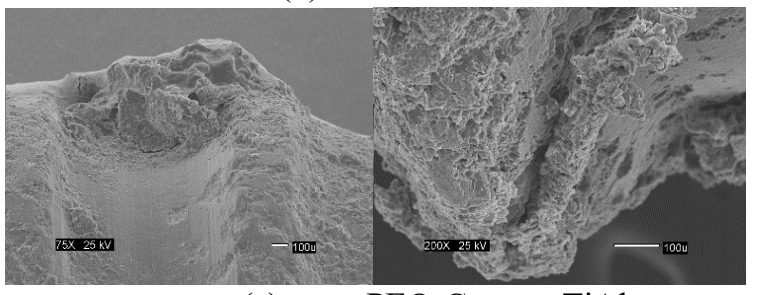

(c)

PEO-Gamma TiAl

Figure 2. Left: SEM images of implant screws after removal from sheep ilia after 3-month implantation (a) Ti6Al4V, (b) $\gamma \mathrm{TiAl}$ and (c) PEO-treated $\gamma$ TiAl implant. Right: Degree of attachment of bone tissue to the implant screw surfaces.

Table 1. Average values of implant removal torque $(n=2)$ for 3 -month and \begin{tabular}{|c|c|c|}
\hline \multirow{2}{*}{ Material type } & Removal Torque $($ N.cm $)$ \\
\cline { 2 - 3 } & 3 months & 6 months \\
\hline Ti6Al4V & 96.03 & 113.42 \\
\hline$\gamma \mathrm{TiAl}$ & 92.65 & $99.03 *$ \\
\hline PEO-treated $\gamma \mathrm{TiAl}$ & 153.10 & 161.83 \\
\hline${ }_{\mathrm{n}} \mathrm{n}=1$
\end{tabular}

Notable differences in bone growth are observed for both untreated and treated cases from histological images between the 3-month and 6-month samples as seen in Figure 3. Although a quantitative histomorphometric analysis was not performed in this study and the amount of bone-to-implant contact was not determined, a relatively small amount of bone growth is observed on the bone tissue side of the interface for the untreated screws after the three-month implant duration, corroborating observation from the SEM images. This is expected in untreated titanium implants where osseointegration is only slightly favored as highlighted by many attempts to alter the topography of the titanium implant surfaces by different treatments to enhance bonding between implant and bone [20-24]. However, in the case of PEOtreated $\gamma \mathrm{TiAl}$, bone growth was clearly observed in the first 3 months specifically around the implant. This growth is attributed to the PEO treatment which creates an in situ oxide while simultaneously incorporating $\mathrm{Ca}$ and $\mathrm{P}$ into the oxide. The resulting complex Ti-Al oxide, has $\mathrm{Ca}$ and $\mathrm{P}$ incorporated in ionic form and not as hydroxyapatite and this will provide a submicron porous scaffold template provided by the PEO layer with $\mathrm{Ca}$ and $\mathrm{P}$ present. This is expected to 
encourage and enhance bonding with the existing bone tissue which will also lay out its own scaffold consisting of a trabecular bone structure and thus, strongly bond to the complex Ti-Al oxide. The de novo bone formed on the PEOtreated Ti alloy surface will result in a higher torque strength due to the increase in the degree of osseointegration. Note that trabecular bone formation occurs only on existing bone for the case of untreated screws. For the PEO-treated screws, trabecular bone growth occurs on the existing bone and also on the oxide surface of the implant. It is suggested that a "ceramic" bone will bond easily with the oxide formed as a result of the PEO process on $\gamma \mathrm{TiAl}$ as compared to a smooth metallic surface available in the case of the untreated screws. Figure 3 shows a schematic illustration of this process.

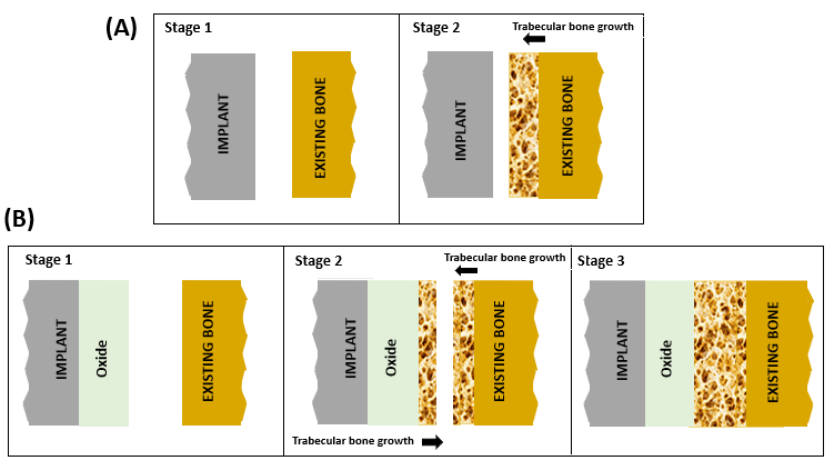

Figure 3. Schematic illustration of the degree of osseointegration for (A) untreated Ti6Al4V and $\gamma$ TiAl screws and (B) PEO-treated $\gamma$ TiAl screws.

Tissue continuity, interrupted by surgical implantation, is quickly restored through the formation of de novo trabecular bone by appositional bone growth [25] as was also observed in the present study. The spicules in trabecular bone grow quickly to occupy the space between the implant and the existing bone tissue soon after surgery. The mechanical strength of this immature tissue is low. In the case of the sixmonth implantation period, histology reveals the presence of de novo bone formation at the implant interface for all three implant screw types as seen by the dark grey stains in Figure 4. While there is a considerable difference in bone growth between the 3-month and 6-month implants for the untreated titanium screws, as highlighted by the dark grey region in the histology samples, a meaningful difference in the generated bone tissue is not noted for the PEO-treated implant screws. We suggest that a relatively greater degree of bone growth in the case of the untreated samples with increased implant duration (from 3 months to 6 months) does not necessarily correlate with enhanced osseointegration of the implant corresponding to the higher torque removal values. Rather, there should be no drastic change in the degree of osseointegration since no chemical bond is formed between the metallic implant surface and the existing bone tissue. On the other hand, the formation of a strong bond between the trabecular bone generated at the bone-implant interface as a result of PEO treatment appears to be implicated in the higher torque strength. Additional duration of the implant merely results in bone modeling and remodeling at the bone-implant interface with no significant increase in the maximum torque values even as the trabecular bone matures into cortical tissue. Our suggestion is supported by the torque removal data in Table 1 where only small increases are observed for both implantation periods for each untreated implant material type. The significantly greater difference in torque removal values for the PEO-treated $\gamma \mathrm{TiAl}$ screw is obvious which clearly suggests an enhancement in osseointegration compared to the untreated samples.
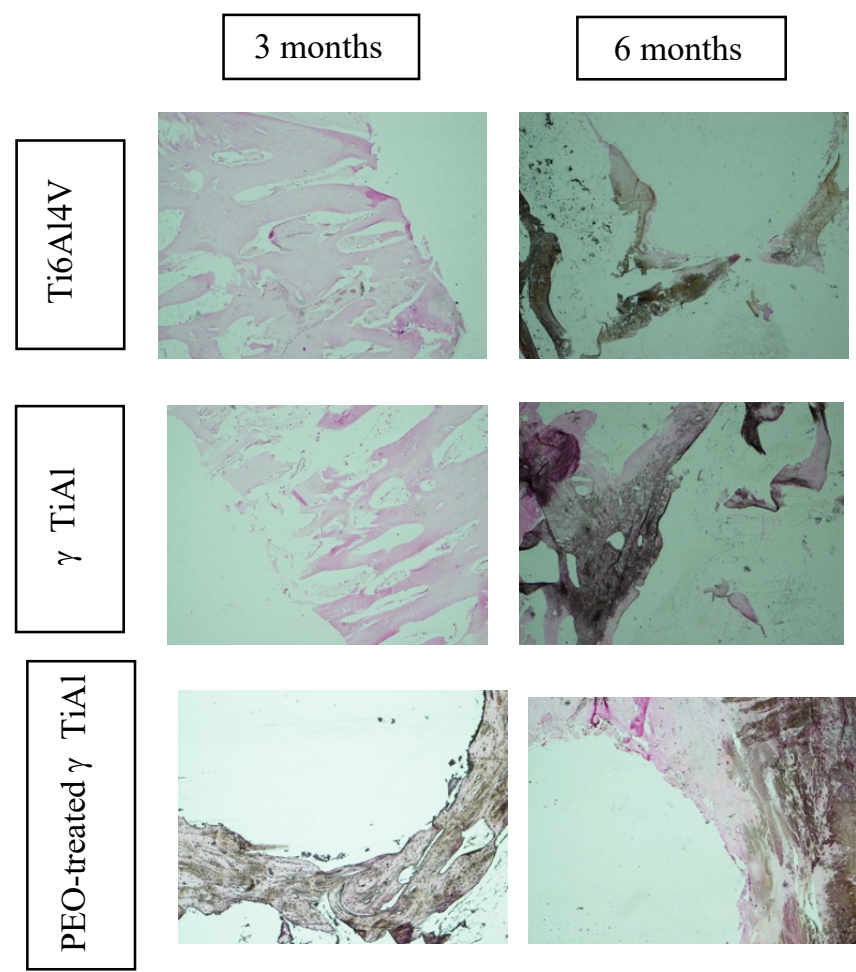

Figure 4. Von Kossa staining of histological samples for Ti6A14V, $\gamma \mathrm{TiAl}$ and PEO-treated $\gamma \mathrm{TiAl}$ after 3-month and 6-month implantations.

Another important issue in the biocompatibility of implant materials is their degradation in the human body environment as a result of localized or uniform corrosion. One of the principal reasons for implant loosening is corrosion/wear of the implant and the subsequent biological reaction of the periimplant tissue with the metallic debris. This reaction with the metal ions released by the implant gives rise to osteolysis. Since metallic particles resulting from wear/corrosion are small (of the order of nanometers), they possess a larger surface area making them extremely effective in eliciting a strong reaction from the extra-synovial tissue [26]. Macrophages normally ingest the small-sized particles and these make their way into the blood stream. The concentration of metal ions in the blood serum reflects a systemic exposure to metal. For example, ionic aluminum $(\mathrm{Al})$, vanadium $(\mathrm{V})$, chromium $(\mathrm{Cr})$ and titanium $(\mathrm{Ti})$ have been reported to cause mutagenic action in cells in tissue culture [27]. Thus, blood serum analysis becomes quite important in estimating the deterioration of the implant in the corrosive environment of the human body. Blood serum analysis for constituent trace elements of the implant materials carried out in this sheep model study using ICPOES is tabulated for the implant period in weeks (see Table 2). 
Table 2. Trace element concentration ( $\mathrm{ppm}$ ) in blood serum of sheep model for 3-month and 6-month implantation and control (no implantation).

\begin{tabular}{|c|c|c|c|c|c|c|}
\hline & \multirow{2}{*}{$\begin{array}{l}\text { Implantation } \\
\text { period } \\
\text { (Weeks) }\end{array}$} & \multicolumn{5}{|c|}{ Concentration (ppm) } \\
\hline & & $\mathrm{Al}$ & $\mathrm{Cr}$ & $\mathrm{Ti}$ & $\mathrm{V}$ & $\mathrm{Nb}$ \\
\hline \multirow{8}{*}{ 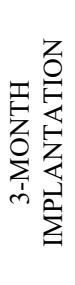 } & 0 & 1.867 & 0.139 & ND & 0.306 & 0.017 \\
\hline & 2 & 0.322 & 0.102 & ND & 0.081 & ND \\
\hline & 4 & ND & 0.100 & $\mathrm{ND}$ & 0.017 & ND \\
\hline & 6 & 2.119 & 0.110 & ND & 0.045 & ND \\
\hline & 8 & 17.960 & 0.121 & ND & 0.065 & ND \\
\hline & 10 & 1.444 & 0.102 & ND & 0.237 & ND \\
\hline & 12 & ND & 0.108 & ND & 0.569 & ND \\
\hline & 14 & ND & 0.108 & ND & 0.630 & ND \\
\hline \multirow{13}{*}{ 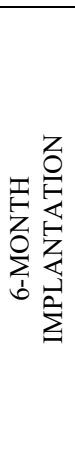 } & & & & DD & & ( \\
\hline & 2 & 7.219 & 0.110 & ND & 0.066 & ND \\
\hline & 4 & 8.431 & 0.032 & $\mathrm{ND}$ & 0.100 & ND \\
\hline & 6 & ND & 0.110 & ND & ND & ND \\
\hline & 8 & ND & 0.099 & ND & 0.164 & ND \\
\hline & 10 & 2.197 & 0.126 & ND & 0.476 & ND \\
\hline & 12 & 2.574 & 0.084 & ND & 0.595 & ND \\
\hline & 14 & 1.683 & 0.100 & $\mathrm{ND}$ & 0.642 & ND \\
\hline & 16 & 8.073 & 0.110 & ND & 0.834 & ND \\
\hline & 18 & 11.980 & 0.125 & $\mathrm{ND}$ & 0.801 & ND \\
\hline & 20 & 10.030 & 0.097 & ND & 1.044 & ND \\
\hline & 22 & ND & 0.099 & ND & 0.635 & ND \\
\hline & 24 & 35.720 & 0.178 & ND & 0.724 & ND \\
\hline \multirow{10}{*}{ 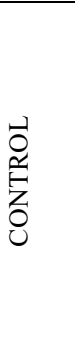 } & 0 & 9.197 & 0.125 & ND & 0.147 & 0.010 \\
\hline & 2 & 11.170 & 0.167 & ND & 0.081 & ND \\
\hline & 4 & 1.063 & 0.111 & ND & 0.075 & ND \\
\hline & 6 & 15.610 & 0.126 & ND & 0.077 & ND \\
\hline & 8 & 11.460 & 0.099 & ND & 0.474 & ND \\
\hline & 10 & 7.210 & 0.118 & ND & 0.624 & ND \\
\hline & 12 & 2.312 & 0.177 & $\mathrm{ND}$ & 0.808 & ND \\
\hline & 14 & 10.670 & 0.114 & ND & 0.705 & ND \\
\hline & 16 & 11.750 & 0.099 & ND & 0.944 & ND \\
\hline & 18 & 3.452 & 0.106 & ND & 0.811 & ND \\
\hline
\end{tabular}

The metallic element detected in the highest amount in the blood serum was $\mathrm{Al}$ while $\mathrm{V}$ and $\mathrm{Cr}$ were present in lower amounts. In contrast, $\mathrm{Ti}$ and $\mathrm{Nb}$ were not detected in blood serum. Al toxicity has been reported to cause neurological and neuropathological conditions including Alzheimer's and Parkinson's diseases [28,29]. Also, chronic Al exposure has been implicated in osteomalacia and pathological fractures [30]. Food is the major source of $\mathrm{Al}$ in the human body and its concentration in the blood serum of healthy individuals is between 1-3 $\mu \mathrm{g} / \mathrm{L}$. The concentration of $\mathrm{Al}$ found in the blood serum of the sheep with implants in this study is relatively high. However, the $\mathrm{Al}$ concentrations in the control animal without an implant are similar. P-values obtained from a single-factor ANOVA were 0.06 (control and 3 month) and 0.10 (control and 6 month). The high content of $\mathrm{Al}$ in the blood serum is attributed to the food source of the sheep. The presence of both $\mathrm{Cr}$ and $\mathrm{V}$ in the blood serum can cause toxicity at high dosages. For comparison, normal levels of these metals in the blood serum is $0.05 \mu \mathrm{g} / \mathrm{L}$. Both these metals are components of enzymes in the human body. $\mathrm{Cr}$ can cause genotoxicity [31] and induces tubular necrosis and interstitial cell damage which can lead to renal impairment [32]. V has been reported to cause implant loosening [28]. In the blood serum of the sheep used in this study, there is no significant difference in the concentrations of $\mathrm{Cr}$ and $\mathrm{V}$ between the control and implanted sheep. For chromium, p- values of 0.11 (control \& 3 month) and 0.06 (control \& 6 month) were determined from single factor ANOVA. For vanadium, p-values of 0.31 (control \& 3 month) and 0.81 (control \& 6 month) were obtained. $\mathrm{Ti}$ and $\mathrm{Nb}$ were not detected by the ICP-OES possibly because of their very low content in the blood serum. The lack of a significant difference in the $\mathrm{Al}, \mathrm{Cr}$ and $\mathrm{V}$ values, combined with the absence of $\mathrm{Ti}$ and $\mathrm{Nb}$ in the blood serum samples of the control, 3-month and 6-month implants indicates that the implants were very stable and suffered little corrosion in the body environment.

\section{CONCLUSION}

In summary, the maximum torque removal values obtained were significantly higher for PEO-treated $\gamma$ TiAl implant screws compared to the untreated $\gamma \mathrm{TiAl}$ and Ti6Al4V screws. SEM images of the extracted screws show trabecular bone tissue adhesion on all three types of implant surfaces, although for PEO-treated $\gamma \mathrm{TiAl}$ samples, the adhesion appears to be much greater. Histology using von Kossa staining supports these observations with a more intense stain corresponding to a larger amount of de novo bone in the periimplant tissue of PEO-treated $\gamma$ TiAl screws. Taken together, this indicates that the PEO treatment enhances osseointegration of $\gamma$ TiAl screws. Blood serum analysis reflects small quantities of metallic elements and no major differences between the control and implant animals, which appears to indicate that all the implants were fairly corrosion resistant in the implant environment.

\section{ACKNOWLEDGMENT}

This research was financially supported by the HHMI Grant No. 52007566. Dr. Alexander Mesonero, Associate Professor, Department of Animal Science, UPR Mayaguez helped with the sheep model. Roberto Torres (Pathology Lab technician) prepared the samples for histology.

\section{REFERENCES}

[1] Y. Okasaki, S. Rao, Y. Ito. Corrosion resistance, mechanical properties, corrosion fatigue strength and cytocompatibility of new titanium alloys. Biomaterials 19 (1998) 1197-1215.

[2] C.N. Elias, J.H.C. Lima, R. Valiev, M.A. Meyers. Biomedical applications of titanium and its alloys. JOM 3 (2008) 46-49.

[3] M. Jatsy. Clinical reviews: particulate debris and failure of total knee replacements. J Appl Biomater 4 (1993) 273-276.

[4] A. Balamurugan, S. Rajeswari, G. Balossier, A.H.S. Rebelo, J.M.F. Ferreiera. Corrosion aspects of metallic implants - An overview. Materials and Corrosion 59 (2008) 855-869.

[5] J. Jacobs, J. Gilbert, R. Urban. Corrosion of metal orthopedic implants. J Bone Jt Surg 80 (1998) 268-282.

[6] P. Sauvé, J. Mountney, T. Khan, J. De Beer, B. Higgins, M. Grover. Metal ion levels after metal-on-metal Ring total hip replacement. $J$ Bone Jt Surg Br 89 (2007) 586-590.

[7] J. Daniel, H. Ziaee, C. Pradhan, D.J. McMinn. Six-year results of a prospective study of metal ion levels in young patients with metal-onmetal hip resurfacings. J Bone Jt Surg Br 91 (2009) 176-179.

[8] J.E. Ellingsen, S.P. Lyngstadaas. Bioimplant interface: Improving biomaterials and tissue reactions, CRC Press 2003 ISBN: 978-0-84931474-2.

[9] M. Kulkarni, A. Mazare, P. Schmuki, A. Iglic. Biomaterial Surface Modification Of Titanium and Titanium Alloys for Medical Applications, in Nanomedicine, Eds: A. Seifalian, A. de Mel, D.M. Kalaskar, One Central Press, 2014 pp.111-136.

[10] S.R. Paital, N.B. Dahotre. Calcium phosphate coatings for bio-implant applications: Materials, performance factors, and methodologies. Mater Sci Eng 66 (2009) 1-70. 
[11] L.H. Li, Y.M. Kong, H.W. Kim, Y.W. Kim, H.E. Kim, S.J. Heo, J.Y. Koak. Improved biological performance of Ti implants due to surface modification by microarc oxidation. Biomaterials 25 (2004) 28672875.

[12] Z. Yao, Z Jiang, X. Wu, X. Sun, Z. Wu. Effects of ceramic coating by microplasma oxidation on the corrosion resistance of Ti6A14V alloy. Surf Coat Tech 200 (2005) 2445-2450.

[13] M. Plecko, C. Sievert, D. Andermatt, R. Frigg, P. Kronen, K. Klein, S. Stübinger, K. Nuss, A. Bürki, S. Ferguson, U. Stoeckle, B. von Rechenberg. Osseointegration and biocompatibility of different implants- a comparative experimental investigation in sheep. $B M C$ Musculoskeletal Disorders 13 (2012) 32-43.

[14] T. Lech, T. Lachowicz. Application of ICP-OES to multielement analysis of biological material in forensic inorganic toxicology. Problems of Forensic Science 78 (2009) 64-78.

[15] J. Versieck. The collection and preparation of human blood plasma or serum for trace element analysis. J Res Natl Bur Stand 91 (1986) 8792.

[16] L. Balcaen, E. Bolea-Fernandez, M. Resano, F. Vanhaecke. Accurate determination of ultra-trace levels of Ti in blood serum using ICPMS/MS. Anal Chim Acta 809 (2014) 1-8.

[17] M.I. Yahaya, A. Shehu, F.G. Dabai. Efficiency of extraction of trace metals from blood samples using wet digestion and microwave digestion techniques. J Appl Sci Environ Manage 17 (2013) 365-369.

[18] E. Newman, A.S. Turner, J.D. Ward. The potential of sheep for the study of osteopenia: current status and comparison with other animal models. Bone 19 (1995) 277S-284S.

[19] A. Nafei, C.C. Danielson, F. Linde, I. Hvid. The properties of growing trabecular ovine bone. Part I: Mechanical and physical properties. $J$ Bone Jt Surg Br 82 (2000) 910-920.

[20] P.-I. Bränemark. Introduction to osseointegration. In P.-I. Bränemark, T.A. Zarb, T. Albrektsson (eds). Tissue-integrated protheses: Osseointegration in Clinical Dentistry. Chicago: Quintessence, 1985: 11-76.

[21] T. Albrektsson, T. Jansson, U. Lekholm. Osseointegrated dental implants. Dent Clin North Am 30 (1986) 151-174.

[22] P. Henry, I. Rosenberg. Single-stage surgery for rehabilitation of the edentulous mandible: Preliminary results. Pract Periodontics Aesthet Dent 6 (1994) 15-22.

[23] D. Buser, H. Weber, N. Lang. Tissue integration of non-submerged implants. 1-year results of a prospective study with hollow cylinder and hollow screw implants. Clin Oral Implants Res 1 (1990) 33-40.

[24] A. Cunha, R.P. Renz, G. Wantowski, R.B. de Oliveira, E. Blando, R. Hubler. A surgical procedure using sheep as an animal model to evaluate osseointegration, Rev Clin Pesq Odontol 3 (2007) 149-157.

[25] A. Probst, H.U. Spiegel. Cellular mechanisms of bone repair. J Invest Surg 10 (1997) 77-86.

[26] V. Sansone, D. Pagani, M. Melato. The effects on bone cells of metal ions released from orthopaedic implants: A review. Clin Cases Miner Bone Metab 10 (2013) 34-40.

[27] B. Daley, A.T. Doherty, B. Fairmann, C.P. Case. Wear debros from hip or knee replacements causes chromosomal damage in human cells in tissue culture. J Bone Jt Surg Br 86 (2004) 598-606.

[28] R.F. Coleman, J. Herrington, J.T. Scales. Concentration of wear products in hair, blood and urine after total hip replacement. $\mathrm{Br}$ Med $\mathrm{J}$ 1 (1973) 527-529.

[29] R.A. Yokel. The toxicology of aluminium in the brain: a review. Neurotoxicology 21 (2000) 813-828.

[30] E.H. Jeffery, K. Abreo, E. Burgess, J. Cannata, J.L. Greger. Systemic aluminum toxicity: effects on bone, hematopoietic tissue, and kidney. J Toxicol Environ Health 48 (1996) 649-665.

[31] I. Papageorgiou, Z. Yin, D. Ladon, D. Baird, A. C. Lewis, A. Sood, R. Newson, I.D. Learmonth, C.P. Case. Genotoxic effects of particles of cobalt chrome alloy on human cells of different age in vitro. Mutat Res 619 (2007) 45-58.

[32] E.F. Madden, B.A. Fowler. Mechanisms of nephrotoxicity from metal combinations: a review. Drug Chem Toxicol 23 (2000) 1-12.

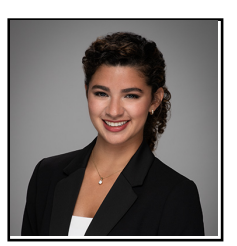

Paola A. Richiez-Nieves obtained her B.S. in Mechanical Engineering from the University of Puerto Rico, Mayaguez in 2016. She is currently working towards an M.D. and hopes to specialize in internal medicine.

Ms. Richiez was a member of the Society of Hispanic Professional Engineers (SHPE), UNICEF, Tau Beta $\mathrm{Pi}$ and the Society of Automobile Engineering (SAE). She participated Puerto Rico's Comprehensive Cancer Center research evaluating Familial Adenomatous Polyposis and Lynch patients. Ms. Richiez is currently a member of American Medical Association, Internal Medicine Interest group and Secretary of Gastroenterology Interest group. She is completing a case series on Von Hipple Lindau Syndrome families in Puerto Rico and their management.

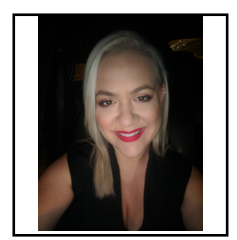

Irimar Torres-Zapata obtained her M.S. degree in Biology in 2012 and her B.S degree in Industrial Microbiology in 2007 from the University of Puerto Rico, Mayaguez, Puerto Rico.

She is currently Associate Quality Analyst in DXC Technology, Isabela PR. Selected publications include (1) Electrochemical Characterization of MC3T3-E1 cells culture on $\gamma$ TiAl and Ti-6Al-4V alloys. J.A. Bueno-Vera, I. Torres-Zapata, P.A. Sundaram, N. Diffoot Carlo and C.A. Olivencia, Bioelectrochemistry 2015;106: 316-324. (2) Generation of large insert metagenomic libraries using indirect DNA extraction methods from benthic and ephemeral tropical hypersaline microbial mats. C. Ríos-Velázquez, I. Torres-Zapata, A. GonzálezMontalvo, C. Castro-Ruiz, Current Research, Technology and Education Topics in Applied Microbiology and Microbial Biotechnology. 2011;2:1569-1575. Current and previous research interests include in microbial/environmental genetics, virology, and interdisciplinary biomedical and bioengineering research with full implementation of eukaryotic tissue culture.

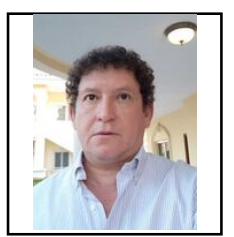

Abner A. Rodríguez-Carías, received his $\mathrm{Ph} . \mathrm{D}$ degree in Ruminant Nutrition from Michigan State University (1996), East Lansing, Michigan, USA. He received his M.S in Animal Nutrition (1990)., and B.S. in Animal Science (1987) degrees from University of Puerto Rico, Mayaguez Campus.

$\mathrm{He}$ is a PROFESSOR of Animal Science at the University of Puerto Rico, Mayaguez Campus (UPRM), where he has been a Faculty member for 24 years with teaching, research, and extension appointments. He was selected to participate in the Stapledon Memorial Fund and the USDA E Kika De La Garza Fellowship programs. Presently, he is a consultant of the Puerto Rico Department of Agriculture Small Ruminant Production Fund. Dr. Rodríguez has been an academic advisor of 29 graduate students that have obtained their M.S. degree and he is author or co-author of over 40 peer review publications and over 150 research reports and abstracts on small ruminant production, ruminant nutrition or silage production. He has been an invited speaker at national, regional and international congresses.

Dr. Rodríguez is member of the International Goat Association, American Society of Animal Science, and the Alpha Zeta and Gamma Sigma Delta honor societies of Agriculture. Dr. Rodriguez was also a volunteer of the "Partners of Americas" and "Winrock International" Farmer to Farmer Program sponsored by USAID, in Latin America (Republics of Guatemala and Nicaragua), and Asia (Bangladesh).

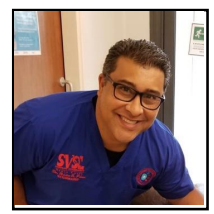

Hector R. Pérez obtained his Doctor in Veterinary Medicine from Kansas State University, Manhattan, Kansas in 1999, M.S. in Animal Science (Reproduction), University of Puerto Rico, Mayaguez, Puerto Rico, 1992 and B.S. in Animal Science, University of Puerto Rico, Mayaguez, Puerto Rico, 1990.

He currently works as Veterinarian in Servicios Veterinarios Santa Lucia at Arecibo, Puerto Rico. Owner of Holistica Life, LLC, Premium Holistics, INC, and My Health Lab, LLC. Reproductive veterinarian at Centro Reproductivo del Caribe. Editor of Mi Mascota Magazine. Professor at Universidad del Turabo, University of Puerto Rico, Interamerican University of Puerto Rico, San Felipe Catholic School. Selected publications include (1) Alternative Medicine (AM) vs Conventional Medicine (CM) in the treatment of chronic diarrhea in rhesus macaques, H.R. Perez, A. Banerjee, C. Padilla, N. Rivera, J.A. Gonzalez, $13^{\text {th }}$ International TCVM Conference Proceedings, 2011, (2) Control of Flea Population on Naturally Infested Pets and in Private Residences with Either Topical Imidacloprid Spot Applications or the Combination of Oral Lufenuron and Pyrethrin Spray, M.W. Dryden, H.R. Perez, D.M. Ulitchny J Am Vet Med Assoc 1999; 215: 36-39. Current research interests include use of nutraceuticals in animals to improve general wellbeing and reproduction.

Dr. Perez is founding member of ALARPA (Asociación Latinoamericana de Reproducción de Pequeños Animales) and member of the Colegio de Médicos Veterinarios de Puerto Rico. 


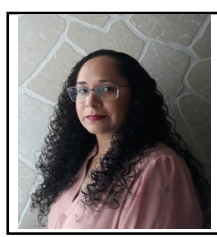

Zilma J. Poueymirou obtained a M.S. degree in in Chemistry in 2006 at the University of Puerto Rico, Mayaguez, Puerto Rico. Her research area was focused on the analytical chemistry, specifically on the development of alternative methodology for the analysis of food matrices.

She currently works as a SCIENTIFIC RESEARCH TECHNICIAN in the materials' area in the Department of Mechanical Engineering at the University of Puerto Rico, Mayaguez campus. She held the position of BIOLOGICAL SCIENCE TECHNICIAN in USDA-TARS, as a graduate researcher in environmental and biotechnology areas, and was an instructor in general and organic chemistry laboratories in the UPR, Mayaguez Puerto Rico.

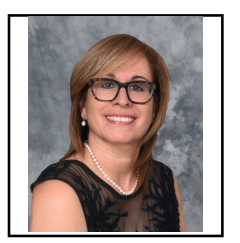

Nanette Diffoot-Carlo obtained her $\mathrm{Ph}$. D. in molecular biology/virology from the Virginia Polytechnic Institute and State University, Virginia, in 1992 and her M.S., genetics, Virginia Polytechnic Institute and State University, Virginia, 1986 and her B. S. Biology, University of Puerto Rico, Mayaguez Campus, Mayaguez, P.R., 1982.

She is currently PROFESSOR in the Department of Biology, University of Puerto Rico, Mayagüez Campus, Mayagüez, PR, where she also was the Director of Department of Biology, University of Puerto Rico from July 2008-Jan. 2016.

Dr. Diffoot-Carlo was HHMI UPR-M Undergraduate Science Program Director (2000-2004, 2008-2016). Recent publications include Study of tissue printing parameters for generating complex tissue constructs, G. Navarro, I. Garcia, P.A. Sundaram, N. Diffoot-Carlo, J Tissue Sci Eng 2016;7:1000175; Vinculin expression in MC3T3-E1 cells in response to mechanical stimulus, J.J. Cora, N. Diffoot-Carlo, P.A. Sundaram, Data in Brief, 2015;6:94-100.

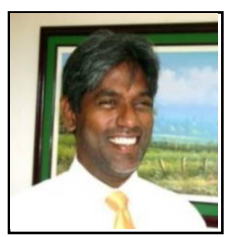

Paul A. Sundaram obtained his Ph.D. in Metallurgical Engineering from the Ohio State University, Columbus, Ohio in 1988

$\mathrm{He}$ is PROFESSOR in the Department of Mechanical Engineering at the University of Puerto Rico in Mayaguez, Puerto Rico where he was CHAIRPERSON from 2003-08 and 2016-18. He is currently on leave with the US Office of Naval Research Global where he serves as SCIENCE DIRECTOR in São Paulo, Brazil. He has held a number of Summer Research Faculty Fellowships with the Army Research Labs and Naval Surface Warfare Center with the US Department of Defense. Selected publications include (1) Adaptive responses of murine osteoblasts subjected to coupled mechanical stimuli, J. Serrano, J. Cora-Cruz, N. Diffoot-Carlo, P.A. Sundaram, J Mech Behav Biomed Mater, 2018;77:250-257,(2) Characterization of plasma electrolytic oxidation coatings on $\gamma$ TiAl intermetallic alloy for orthopedic applications, L. Lara Rodriguez, P.A Sundaram, E. Rosim-Fachini, A. Padovani, N. Diffoot-Carlo, J Biomed Mater Res B, 2014:102:988-1001. Current and previous research interests include biomaterials, biomechanics, cell mechanics and mechanotransduction.

Prof. Sundaram is a member of the Biomedical Engineering Society, Phi Kappa Phi and Golden Key Honor Societies and an active reviewer of many international journals. 